\title{
Cartografía y nación en América Latina (siglos XIX y XX): una aproximación a los casos de Argentina, México y Colombia
}

\section{CARTOGRAPHY AND NATION IN LATIN AMERICA (19TH AND 20TH CENTURIES): AN APPROACH TO THE CASES OF ARGENTINA, MEXICO AND COLOMBIA}

\author{
CARTOGRAFIA E NAÇÃO NA AMÉRICA LATINA (SÉCULOS XIX E XX): UMA \\ APROXIMAÇÃO PARA OS CASOS DE ARGENTINA, MÉXICO E COLOMBIA
}

Para citar este artículo: Osorio-Merchán, Y. y Delgado, J. D. (2019). Cartografía y nación en América Latina (siglos XIX y XX): una aproximación a los casos de Argentina, México y Colombia. Perspectiva Geográfica, 24(2), 49-68. doi: 10.19053/01233769.8624
Yelitza Osorio Merchán ${ }^{1}$

Juan David Delgado ${ }^{2}$

\section{Resumen}

El presente artículo tiene por objetivo aproximarse a la manera en que la geografía y la historia han abordado la relación entre producción cartográfica y formación del Estado nación en Argentina, México y Colombia durante el siglo XIX y parte del XX. Por medio de la revisión de la producción de algunos autores sobre el tema, se pretende mostrar la existencia de una transformación en la manera de abordar la historia de la cartografía en América Latina. Dicho cambio se manifiesta en el hecho de considerar el mapa como algo que no solo se refiere al estado de la técnica en un periodo específico, sino que se vincula al mundo de la representación y de las

Recepción:

14 de noviembre de 2018

Evaluación:

17 de julio de 2019

Aprobación:

26 de septiembre de 2019

1 Geógrafa, Universidad Nacional de Colombia. Candidata a magíster en Geografía, Universidad Nacional Autónoma de México. Investigadora independiente. yelitzaosoriomerchan@ gmail.com

2 Profesor investigador del Programa de Geografía, Área de Cultura y Sociedad, Facultad de Ciencias Sociales y Humanas, Universidad Externado de Colombia. juand.delgado@uexternado.edu.co 
relaciones de poder, como instrumento clave en la consolidación geopolítica de los Estados nacionales latinoamericanos. Se busca, además, evidenciar algunas líneas de trabajo común, así como identificar temas específicos según cada país.

Palabras clave: cartografia, frontera, modernización, nación, territorio.

\section{Abstract}

This article aims to approximate the way in which geography and history have addressed the relationship between cartographic production and nation-state formation in Argentina, Mexico and Colombia during the 19th century and part of the 20th century. Through a review by some authors on the subject, it is intended to show the existence of a transformation in the way of addressing the history of cartography in Latin America. This change is manifested in the fact of considering the map as something that not only refers to the state of the art in a specific period, linking it to the world of representation and power relations, as a key instrument in the geopolitical consolidation of Latin American national states. It also seeks to demonstrate some common lines of work, as well as identify specific issues by country.

Keywords: border, cartography, modernization, nation, territory.

\section{Resumo}

Este artigo tem como objetivo aproximar a maneira pela qual a geografia e a história abordaram a relação entre produção cartográfica e formação de estado-nação na Argentina, México e Colômbia durante o século XIX e parte do século XX. Com uma revisão de alguns autores sobre o assunto, pretende-se mostrar a existência de uma transformação na maneira de abordar a história da cartografia na América Latina. Essa mudança se manifesta no fato de considerar o mapa como algo que não se refere apenas ao estado da arte em um periodo especifico, vinculando-o ao mundo das relações de representação e poder, como um instrumento fundamental na consolidação geopolítica de Estados nacionais da América Latina. Também procura demonstrar algumas linhas de trabalho comuns, além de identificar questões especificas por país.

Palavras chave: cartografia, fronteira, modernização, nação e território. 


\section{Introducción}

Como producto de un complejo saber científico, el mapa se ha visto, por lo general, como una representación gráfica de la superficie terrestre matemáticamente sustentada. Se le considera como una imagen objetiva y diáfana del territorio que muestra lo que efectivamente "está ahí", es decir, se asume como un dispositivo que presenta, por medio de rasgos gráficos abstractos (puntos, líneas y polígonos), los elementos "reales" del espacio físico y humano.

Sin embargo, este artículo tiene el propósito de destacar un cambio importante en la forma en que se analiza la cartografía y en particular la cartografía nacional, ya que busca poner el acento en la manera en que se ha venido cuestionando la naturaleza neutra de los mapas y su faceta de imagen objetiva del territorio y de la nación (Harley, 2005). En este cambio, acaecido en los ámbitos de la geografía y la historia del siglo XXI, se ha visto la necesidad de "reinsertar la imagen [cartográfica] en su tiempo, en su geografía y en su sociedad" (Mendoza \& Lois, 2009, p. 10), lo que permite al análisis cartográfico ir más allá del ámbito positivista, instalándolo en coordenadas próximas al pensamiento crítico y la teoría social. Es decir, se inserta en un marco interpretativo propio del giro cultural y espacial, que invita a dudar del conocimiento científico y a develar su carácter discursivo tamizado por la cultura, la ideología y las relaciones de poder (Said, 1990). Indudablemente, el estudio de esta "nueva naturaleza de los mapas" ha llamado poderosamente la atención y ha marcado puntos de encuentro entre geógrafos, historiadores, antropólogos, artistas, ingenieros, etc.

Al ser una de las imágenes más recurrentes de la nación, el mapa es también una representación Vol. 24 N. ${ }^{\circ} 2$ julio - diciembre de 2019 pp. $49-68$ simbólica de su "cuerpo geográfico" (Winichakul, 1994). En este sentido, perspectivas recientes en torno a la cartografía consideran necesaria la deconstrucción de postulados largamente decantados en la imaginación geográfica nacional, que asumen el mapa como un instrumento que tiene la capacidad de mostrar, gráficamente, qué o quiénes están dentro y fuera de la nación, al tiempo que puede vérselo como herramienta de legitimación de proyectos expansivos y "deseos territoriales" de quienes detentan el poder (Lois, 2009a).

Los mapas y las geografías nacionales, producidas en el siglo XIX e inicios del XX, estuvieron asociados a importantes procesos de modernización económica que se llevaron a cabo en la región. Según el geógrafo Jean Paul Deler, durante este periodo "el espacio latinoamericano fue transformado profundamente por los efectos de un nuevo movimiento de integración económica del subcontinente al mercado mundial y de consolidación de los territorios de los Estados Nacionales" (Deler, 2008, p. 33).

En este proceso de reordenamiento económico de los espacios nacionales, la cartografía contribuyó de manera eficaz a la construcción de una soberanía territorial. Las comisiones geográficas o corográficas fueron punta de lanza fundamental para identificar recursos, poblaciones estratégicas y establecer fronteras, entre otras tareas. Lo hicieron Claudio Gay en Chile (1830-1842) (Sagredo, 2009), Agustín Codazzi en Venezuela y la Nueva Granada (1850-1859) (Sánchez, 1998) y Agustín Díaz en México, en el marco de la Comisión Geográfico-Exploradora (1878-1914) (García, 1975), entre otros casos.

El mapa responde entonces a la necesidad de crear, por medio de un discurso visual (Lois, 2009b), una 
"comunidad imaginada" en donde valores como el compañerismo y la horizontalidad tienen un referente espacial común, es decir, se producen en un lugar, en una "tierra natal" demarcada por un "mapa cognitivo" de la nacionalidad (Smith \& Núñez, 1998, p. 61). Así la cartografía trasciende su perspectiva funcional (una técnica "útil" al capital) y evidencia una interesante faceta ligada a su condición de símbolo nacional.

En síntesis, el presente artículo tiene por objetivo realizar una aproximación a lo que se ha escrito en las últimas dos décadas sobre la relación entre cartografía y nación en tres casos particulares de América Latina (Argentina, Colombia y México). De esta manera, el artículo se organiza temáticamente en tres partes, cada una de las cuales corresponde a un "caso nacional", en donde se exponen las características de los trabajos producidos sobre la cartografía del periodo en cuestión.

\section{Argentina: la geografía}

\section{nacional y la conquista del "desierto"}

En buena medida, la producción académica sobre la relación entre cartografía y nación en la Argentina ha tenido como eje de análisis los procesos de conquista y colonización de la pampa, el Chaco y la Patagonia llevados a cabo en la transición de los siglos XIX y XX. Esta tendencia en el análisis ha tenido en la geógrafa e historiadora Carla Lois un referente importante, al identificar tres procesos que dinamizaron la producción cartográfica durante este periodo: el reconocimiento de los territorios indígenas, los límites internacionales y los esfuerzos por producir mapas científicamente sustenta- dos, temas que, a su vez, responden a los proyectos económicos y geopolíticos del Estado argentino de aquel periodo (Lois, 2009a).

En relación con los territorios indígenas, Lois subraya que la cartografía representó y acentuó de diversas maneras la antinomia civilización-barbarie. De ahí que a partir de 1880 , en consonancia con las campañas militares sobre las tierras indias, la cartografía militar se propusiera dar cuenta, gráficamente, del avance "civilizatorio" utilizando estrategias visuales para destacar la expansión de los "blancos", mientras pretendía diluir la presencia indígena y de sus tolderías, asociándolas gráficamente a íconos que representan áreas de espesa vegetación. Un ejemplo de la representación gráfica de la frontera entre "civilización y barbarie" puede verse en "Plano general de la nueva línea de fronteras sobre la Pampa", elaborado por el Sargento Mayor Dn. Jordan Wysocki en 1877 (Figura 1).

Cabe destacar el origen castrense de esta cartografía de "borramiento" impulsada desde la Oficina Topográfica Militar (1884) y luego con el Instituto Geográfico Militar (1904). Según Lois, estos mapas tuvieron el propósito de anticipar la realidad y graficar "deseos territoriales", que corresponden a “iconografías de un proyecto de nación más que a topografías operativas para el manejo administrativo de esa masa territorial" (Lois, 2009a, p. 256) ${ }^{3}$.

Junto a la Campaña del Desierto (1879), la Conquista del Chaco (1884) fue otro proceso de expansión que contribuiría a la consolidación territorial

3 Esta forma de anticiparse o construir una realidad funcional a los intereses del poder no fue exclusiva de la cartografía. También la estadística y particularmente los censos de población contribuyeron al desvanecimiento o supresión de los pueblos indígenas, así como a la construcción de una "realidad étnica" en la cual el proceso de fusión racial, el denominado "crisol argentino", se encontraba mucho más avanzado en el discurso que en la práctica. Al respecto, ver Otero (2006, cap. 7). 
de Estado argentino. Aquí, Lois se cuestiona sobre la producción cultural de una de las imágenes territoriales que más transcendió y se incorporó en el imaginario nacional argentino de finales del siglo
XIX: el desierto (Lois, 1999), y muestra cómo este término también fue aplicado al Chaco, una región poseedora de una ecología muy distinta a la de un "desierto".

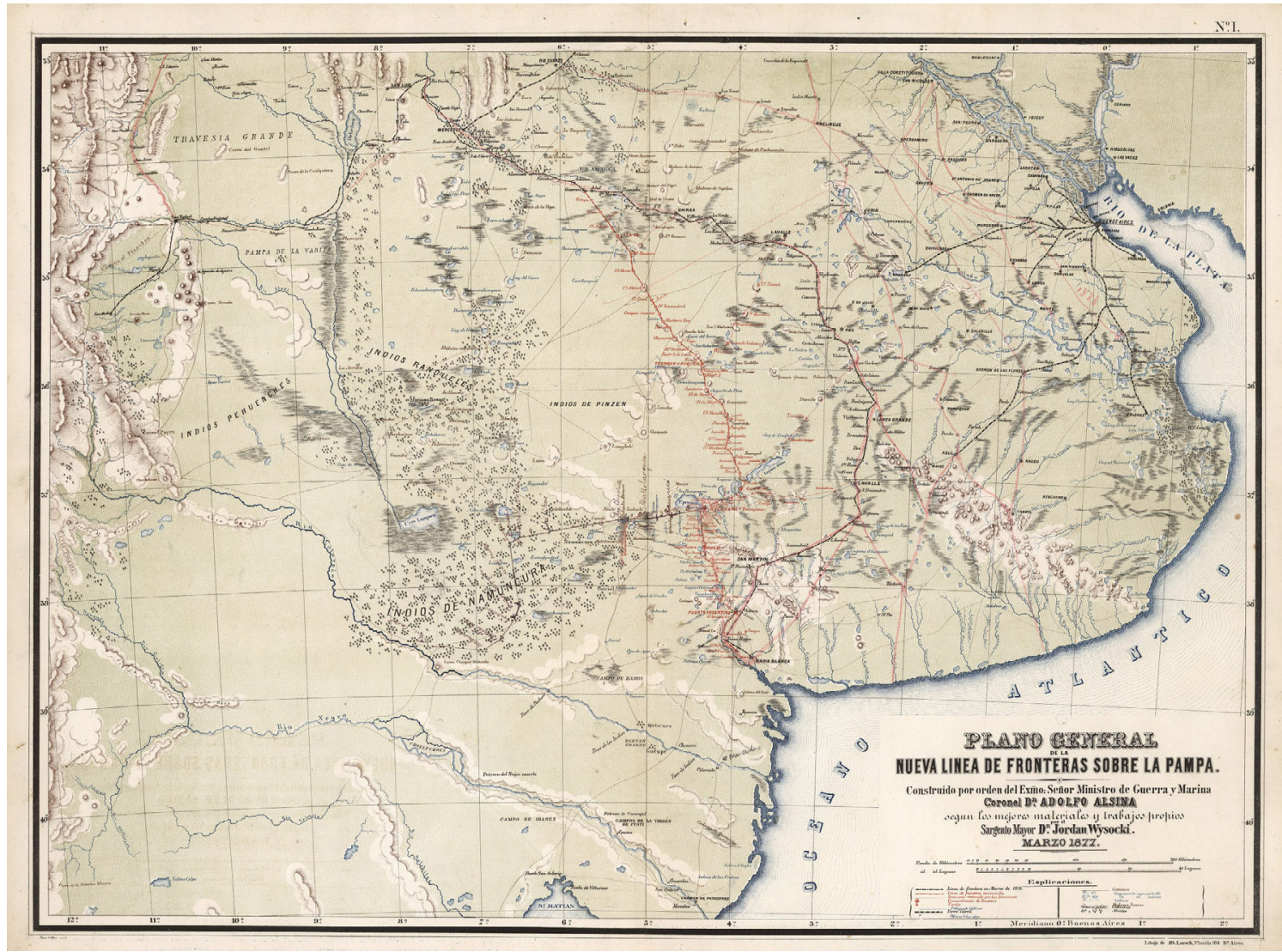

\section{FIGURA 1.}

"Plano general de la nueva línea de fronteras sobre la Pampa": construido por orden del Colonel Dn. Adolfo Alsina [...] Por el Sargento Mayor Dn. Jordan Wysocki (marzo de 1877).

Fuente: David Rumsey Historical Map Collection.

Lois sostiene que dicha conceptualización del Chaco hizo parte de un discurso que tenía la función de legitimar la apropiación, por parte del Estado y los concomitantes intereses privados, de un territorio potencialmente apto para la explotación agrícola pero largamente ocupado por grupos indígenas "hostiles". Así, la conquista del desierto chaqueño buscaba no solo constituir límites internacionales y acotar fronteras interiores, sino también crear y "socializar imágenes oficiales y estandarizadas del territorio nacional, de manera tal que fuera posible la construcción de referentes patrióticos que actúen como aglutinadores y como diferenciadores" (Lois, 1999).

No obstante, se destaca el carácter diferencial que tuvo la campaña del Chaco respecto de la llevada a cabo en la pampa. Aquí, en lugar del aniquila- 
miento del indio, se buscó la manera de "incorporarlo" a la nación y al desarrollo regional mediante su vinculación como mano de obra en ingenios y obrajes. En este orden, Lois y Troncoso (1998) relacionan dicho cambio de actitud hacia los pueblos indígenas con la intermediación de la Sociedad Geográfica Argentina (SGA), institución que acompañó dicha expansión, hizo algunas prospecciones etnográficas y cartografió el área. Sin embargo, pese al replanteamiento de la cuestión indígena, las autoras consideran que la SGA no escapó de la intención "por descubrir las 'leyes naturales' que asegurarían el triunfo de la civilización o, cuanto menos, legitimarían las operaciones políticas que se empeñaran por imponerla" (Lois y Troncoso, 1998).

Por su parte, en relación con la conquista y colonización de la Norpatagonia, Pedro Navarro discute la pluralidad ideológica de los discursos que emanan de las principales instituciones geográficas relacionadas con dicho proceso. Establece un contrapunto entre las ideas propuestas por el Instituto Geográfico Argentino (IGA) y la ya mencionada SGA, donde el primero es de un talante más cercano a los intereses del Estado y del colonialismo externo, mientras que la segunda apostaba por una postura más "científica" y "crítica" respecto al proceso de conquista y colonización.

No obstante, Navarro plantea que ambas instituciones coincidieron, una vez consumada la apropiación del territorio por parte del Estado argentino, en el desmantelamiento del imaginario geográfico del desierto, el cual, si bien legitimó el proceso de expansión hacia el interior y la derrota de los indígenas, ya no era funcional a un modelo de desarrollo y colonización "civilizado", por lo cual es sustituido por un "proyecto espacial de futuro" asociado a la interesante idea de "paisaje de progreso". Coincidiendo con Lois en cuanto al papel relativamente crítico de la SGA, Navarro considera que esta institución se preocupó por los factores humanos, el desarrollo endógeno y la cuestión indígena, conformando una línea disidente y, si se quiere, "progresista" sobre la colonización de esta región (Navarro, 2006).

La idea de "paisajes de progreso" es también abordada por la geógrafa argentina Perla Zusman, quien analiza el relato que hace Domingo Faustino Sarmiento de su viaje por los Estados Unidos en 1847. Presta atención a las observaciones que el futuro presidente argentino realizó respecto al desarrollo de los ferrocarriles, la navegación fluvial y los canales, los cuales le permitieron visitar una asombrosa cantidad de lugares en corto tiempo y experimentar un efecto de contracción espaciotemporal. Así, en la mirada de Sarmiento respecto a los Estados Unidos se evidencia una sociedad llena de virtudes, dinámica y en movimiento, que se desenvuelve en un espacio lleno de recursos naturales y "vacío de población".

Esta concepción de territorio vacío, salvaje y por colonizar, aplicada a los sucesivos "oestes norteamericanos", es un imaginario similar a la noción de desierto con que se asoció a la pampa argentina mientras estuvo controlada por los indígenas. Zusman muestra cómo el viaje por los Estados Unidos le permite a Sarmiento construir una serie de "proyectos geopolíticos" que tratará de aplicar luego a la Argentina en formación (Zusman, 2006) ${ }^{4}$.

4 Respecto a la expansión estadounidense hacia el oeste, Donald Meinig (2000) cuestiona aquella imagen de la "diáspora civilizadora" en la "tierra de la libertad y la democracia", presentando en su lugar una historia signada por el despojo, la violencia y la segregación espacial de diversas naciones indias, así como por el frío cálculo geopolítico de una élite gobernante que si bien proyecta una nación de magnitud continental, debe enfrentar la in- 
Finalmente, en relación con la colonización de la Patagonia, también deben tenerse en cuenta las formas de apropiación y representación del territorio que se realizaron desde las colonias de extranjeros que allí se asentaron. En este sentido, Fernando Williams analiza la cartografía que produjeron colonos galeses en la región de Chubut en el año de 1865 (Williams, 2009). Particularmente destaca la obra cartográfica del ingeniero gales Llwyd Ap Iwan, quien desarrolló una cartografía regional en donde los toponímicos aparecían tanto en lenguas nativas como en galés y prescindía en sus mapas de la utilización tanto de castellano como del inglés. Williams considera que la interrelación entre toponímicos indígenas y galeses pretendía generar un cierto efecto de naturalización de la presencia de esta colonia extranjera y de su cultura en el territorio patagónico (Williams, 2009).

Puede verse, entonces, cómo en el caso argentino se consolida un grupo importante de estudios cuyo propósito es deconstruir el imaginario geográfico de la conquista de los distintos desiertos, mostrando acciones y discursos diferenciales por parte del Estado según se haga referencia a la pampa, el Chaco o la Patagonia.

\section{México: la imagen}

\section{cartográfica nacional, las}

\section{fronteras y los deslindes locales}

En México, puede decirse que los intereses en torno al análisis de la relación entre cartografía y nación han gravitado en cuatro aspectos fundamentales: a) la institucionalización de la geogra-

quietante presencia de otras potencias imperiales en dicho espacio. fía-cartografía, b) la construcción de imaginarios geográficos de la nación, c) la preocupación del Estado por la fijación de las fronteras internacionales y d) el estudio de la construcción cartográfica del espacio local.

En relación con el primer punto, debe decirse que durante el siglo XIX y específicamente durante el porfiriato (1876-1910) la cartografía mexicana experimentó una importante transformación en sus técnicas de análisis y representación del espacio, al tiempo que la geografía se profesionalizaba como campo científico. En este contexto, el geógrafo José Omar Moncada aborda el proceso de institucionalización de la disciplina durante este periodo (Moncada, 1999, p. 63), destacando el papel del Colegio de Minería en la formación de ingenieros geógrafos y geólogos. Moncada muestra que entre 1856 y 1917 se titulan 18 ingenieros geógrafos, algunos de los cuales llegan a ocupar importantes cargos dentro de la administración porfiriana. Sin embargo, a diferencia de los análisis mencionados en el caso anterior, el planteamiento de Moncada tiende a ser descriptivo y poco crítico respecto a la relación entre la cartografía y el proyecto de nación vigente en este periodo.

Omite considerar, por ejemplo, que la profesionalización de la disciplina en el Colegio de Minería era directamente proporcional a la acentuación de un modelo minero-exportador que buscaba conectar y abrir el país tanto a los mercados internacionales como a la inversión e inmigración extranjera. En este orden, siguiendo a las historiadoras Sandra Kuntz y Elisa Speckman (2010), entre 1876 y 1910 se llevó a cabo un importante proceso de expansión y consolidación económica, en donde "se construyeron vías de ferrocarril que unieron el país y permitieron ampliar los mercados; se intensificó 
la producción minera y agrícola y se consolidó el sector de la economía orientado a la exportación" (p. 506). Claramente, el expresado incremento en la conectividad no solo buscaba la consolidación de un espacio económico nacional, sino que tam- bién tenía entre sus objetivos principales el entronque con la red ferroviaria estadounidense, tal como puede evidenciarse, por ejemplo, en el mapa elaborado por el coronel Bodo von Glumer entre 1895 y 1896 (Figura 2).

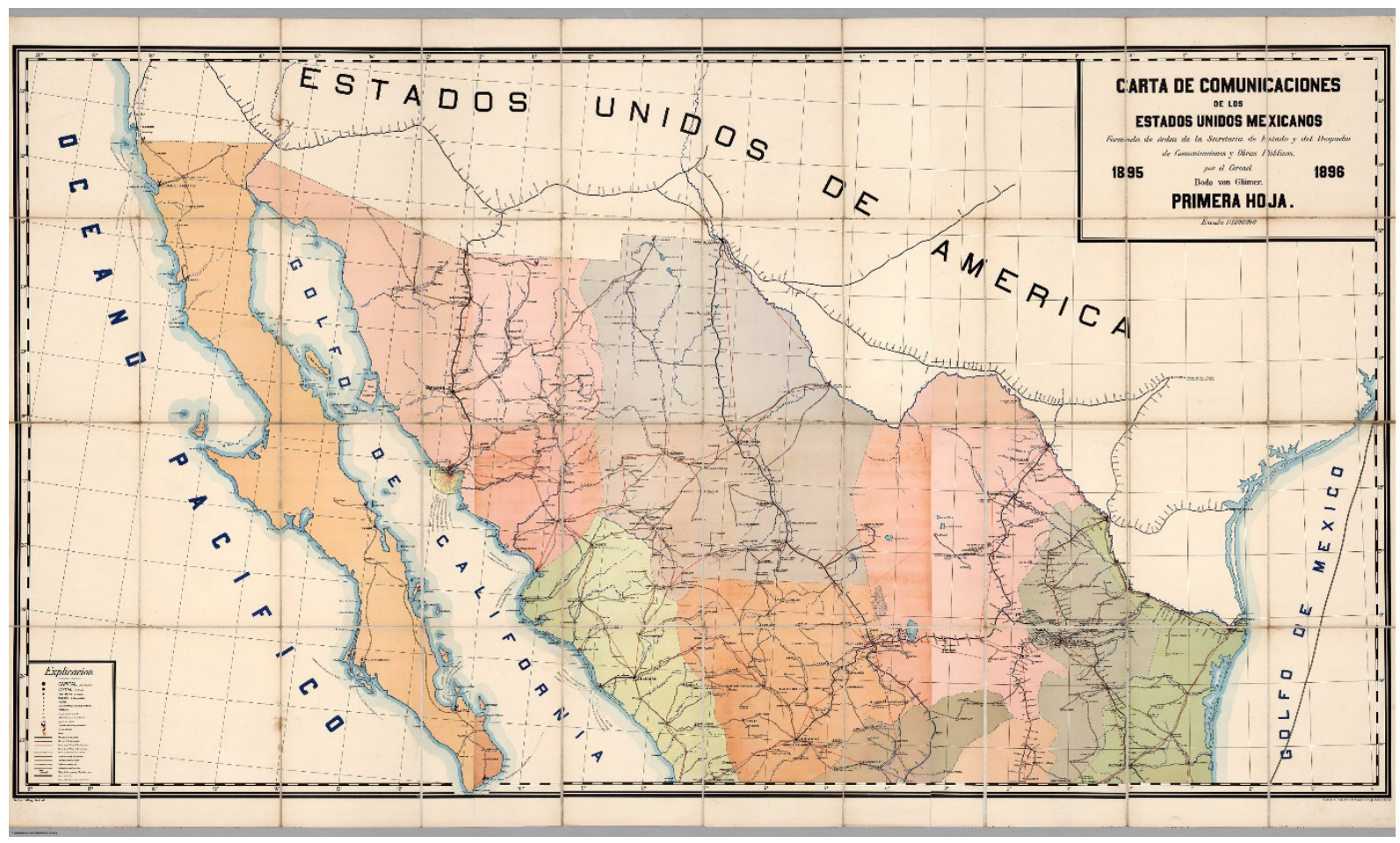

FIGURA 2.

"Carta de Comunicaciones de los Estados Unidos Mexicanos": formada de orden de la Secretaría de Estado y del Despacho de Comunicaciones y Obras Públicas, por el coronel Bodo von Glumer, primera hoja (1895-1896).

Fuente: David Rumsey Historical Map Collection.

Dado el auge del modelo exportador, donde los minerales tenían un peso importante, la geología y en particular la cartografía geológica experimentaría un significativo desarrollo. En este contexto, Héctor Mendoza y Silvia de Mendoça consideran que en la construcción geográfica de las naciones latinoamericanas no solo había que demarcar fronteras y consolidar una imagen de la superficie ocupada por un país, sino que también se involucraba la prospección y explotación de los recursos y riquezas que reposaban en las "entrañas de la tierra" (Mendoza \& Mendoça, 2009).

Aquí, los autores analizan, en una perspectiva comparada, los esfuerzos estatales en la construcción del mapa geológico de México y Brasil entre 1850 y 1900. Destacan que en ambos países se implanta el modelo del Geological Survey estadounidense 
como una manera de independizar la prospección geológica de otras comisiones científicas, así como de darle una organización interna y un marco institucional. En ambos casos, el objetivo era producir cartografía geológica, hacer levantamientos de tierras para la agricultura y obras civiles (geotecnia) y localizar minerales económica y políticamente estratégicos (Mendoza \& Mendoça, 2009, p. 467).

Resulta interesante el argumento de Mendoza y Mendoça referido a que no solo condicionantes de tipo económico impulsaron el desarrollo de los mencionados servicios geológicos. También actuaron vectores culturales e ideológicos que atravesaban la mentalidad de las élites mexicanas y brasileras, lo cual se relacionaba con la imagen de nación que deseaban proyectar, por ejemplo, en las exposiciones internacionales, muy en boga a finales del siglo XIX. Así, los mapas geológicos $\mathrm{y}$ las muestras mineralógicas no solo eran una invitación al inversor extranjero, sino que también eran una muestra de modernidad y civilización, de conocimiento científico de las profundidades del territorio nacional.

Sin embargo, cada experiencia marca sus particularidades. En México se cuenta con una muy amplia tradición en geología aplicada, la cual puede rastrearse desde fines del periodo colonial con Andrés del Río y el propio Humboldt, herencia que sería recogida por Antonio del Castillo, quien proyecta e institucionaliza esta ciencia durante el porfiriato. En Brasil puede decirse que el impulso fue más reciente y vino desde fuera, principalmente con la llegada del geólogo canadiense Charles Hartt en 1863. Allí logra crear la Comisión Geológica de Brasil en 1875, mientras que la de México se formaría hasta 1889. México avanzaría hacia una geología del petróleo en la primera mitad del siglo
XX y Brasil haría lo propio en relación con los metales preciosos (Mendoza \& Mendoça, 2009).

Pasando al segundo punto, referido el análisis de las visiones de conjunto o imaginarios geográficos de la nación, los geógrafos José Moncada y Patricia Gómez analizan las ideas de dos figuras de la intelectualidad mexicana de la primera década del siglo XX: Justo Sierra y Andrés Molina Enríquez (Moncada \& Gómez, 2011). Según los autores, en México: su evolución social (1900-1902), Justo Sierra asume el territorio como un elemento consustancial a la existencia del Estado, el cual hace viable y sustenta la existencia de aquel "organismo colectivo" que es la nación. Por su parte, Andrés Molina Enriques, imbuido en el pensamiento spenceriano, consideraba que la sociedad era un organismo en formación íntimamente relacionado con el suelo de origen, de ahí que considerase que "el vínculo estable entre sociedad y Estado es la tierra y éste fue el principio con que llevó a cabo su crítica a las relaciones de propiedad dominantes en aquella época" (Moncada \& Gómez, 2011, p. 224). Según los autores, en Molina Enríquez se encuentra el germen de la idea que considera el carácter público o nacional de los bienes naturales, sobre todo aquellos del subsuelo, cuestión que quedaría plasmada en el artículo 27 de la Constitución mexicana de 1917 (Moncada \& Gómez, 2011).

De igual forma, durante el porfiriato llegarán nuevas ideas geográficas que son incorporadas en el pensamiento de intelectuales y políticos de la época. En este orden, la geógrafa Patricia Gómez indaga sobre la influencia de las ideas del geógrafo alemán Friedrich Ratzel en el desarrollo tanto de la geografía como de la antropología mexicana de la primera mitad del siglo XX. Gómez menciona que las ideas ratzelianas tuvieron cabida entre miem- 
bros de la Sociedad Mexicana de Geografía y Estadística, quienes veían al Estado desde una óptica organicista, ligado al espacio, pero sobre todo a un "suelo vital" y en donde los Estados más fuertes podían expandirse sobre aquellos "organismos más débiles".

A su vez, considera que la noción de difusionismo fue uno de los principales aportes de Ratzel a la antropología y la geografía mexicanas, que configuró una línea de influencia que involucra, entre otros, a Franz Boas, Manuel Gamio y a Paul Kirchhoff, este último con el concepto difusionista de Mesoamérica como área cultural. Pese a no realizar una clara exposición de las principales tesis del geógrafo alemán, Gómez considera que las ideas políticas de Ratzel influyeron en la forma en que desde el Estado porfiriano se concibió el territorio y la población mexicana (Gómez, 2006).

En cuanto al tema de las fronteras, debe mencionarse que durante el siglo XIX se expresaron incertidumbres espaciales que llevaron al Estado mexicano a construir información geográfica que permitiera establecer con cierta claridad los límites norte y sur del territorio nacional. En este orden, Salvador Álvarez (2011) plantea que el México de este periodo enfrentó dos importantes problemáticas territoriales, en buena medida heredadas de la organización espacial novohispana.

Una de ellas es la indefinición de las fronteras tanto del norte como del sur y la otra fue el poco "empuje demográfico" que experimentaba el México de aquel periodo, destacando así la visión casi premonitoria de Simón Tadeo Ortiz, quien, para 1832, considera que si no se poblaban con premura los territorios más distantes de la república resultaría inminente su pérdida. Dicha premonición se haría realidad y para 1848 la Comisión de Estadística Militar se dio a la tarea de delimitar, en conjunto con una comisión estadounidense, la línea divisoria entre México y Estados Unidos, en el marco de Tratado de Guadalupe Hidalgo (Álvarez, 2011).

Por el lado de la frontera sur, luego de algunos tempranos diferendos con las Provincias Unidas del Centro de América y luego con Guatemala, Álvarez menciona que con la ocupación militar de la región de Soconusco, en 1840, el Estado mexicano logra reforzar su presencia en el borde sur, pese a que la línea fronteriza permanecería indeterminada durante buena parte del siglo XIX. Sería a finales de dicho siglo que se conforma la Comisión Mexicana de Reconocimiento de la Frontera entre México y Guatemala, la cual inicia sus trabajos en 1877 y llega a un tratado formal de límites en 1882, proceso que se adelanta gracias al avance tecnológico e institucional de la geografía y la cartografía del momento. Si bien el texto de Álvarez puede enmarcarse en una historia de la formación del cuerpo geográfico de la nación, esta se hace desde un marco meramente institucional, asociando de manera unidireccional y poco crítica la noción de frontera con la de límite (Álvarez, 2011). Finalmente, la cuarta perspectiva, relativa a la construcción cartográfica del espacio local, tiene en el trabajo del historiador y geógrafo estadounidense Raymond Craib (2004) un referente importante. Su investigación, centrada en el México posrevolucionario, plantea que la historia del moderno Estado mexicano está íntimamente ligada

5 Otros enfoques en relación con la cuestión de la frontera la asumen desde una perspectiva de mayor complejidad, asociada a la construcción social, política y cultural del espacio. Así, por ejemplo, para Cynthia Radding (2008) la frontera es un espacio híbrido en el cual se desarrollan las interrelaciones entre dos o más grupos culturales o formaciones sociales diferenciadas. 
con el espacio, no solo material, sino el que ha producido discursivamente. El propósito de Craib es examinar el proceso social por medio del cual las exploraciones, las mediciones topográficas y las cartografías han definido, codificado y naturalizado el espacio local. En este orden, su aporte radica en destacar la participación, la negociación y la resistencia de las personas y las sociedades que se encuentran en el terreno al momento en que el Estado llega con algún proyecto de medición o producción de espacio racionalizado. Asume la creación del Estado nacional como un proceso de naturalización y normalización, cuya formación implica definir, mapear y nombrar la "realidad" (Craib, 2004, p. 2).

La propuesta de este autor difiere de la línea general de trabajos que abordan la relación entre cartografía y nación al centrase en una escala detallada y analizar, por ejemplo, los múltiples diferendos limítrofes entre dos pueblos veracruzanos antes, durante y después de los procesos de reforma agraria, lo cual evidencia la existencia de geografías y cartografías a escala local y regional que muestran una construcción "desde abajo" de lo que podría denominarse como el "cuerpo geográfico de la nación".

Dichos conocimientos espaciales toman forma a partir del encuentro, negociado y conflictivo, entre los representantes del Estado y los habitadores de los territorios. Craib plantea una oportuna crítica a lo que considera como el "estrecho molde" en el cual se ha construido la historia de la cartografía en México y América Latina, en donde tiende a persistir una mirada "desde arriba", centrada en figuras pertenecientes a las élites letradas, urbanas, y gobernantes que históricamente han pretendido monopolizar el conocimiento geográfico.
Considera entonces que hay que "ampliar" la noción de cartografía para incorporar otros actores y otros procesos, razón por la cual, en lugar de mapas físicos o grandes comisiones corográficas, analiza "los mapas mentales que los campesinos tenían de sus tierras y deslindes, así como el efecto de tales concepciones sobre los esfuerzos de los burócratas para distribuir y cartografiar los terrenos" (Craib, 2009, p. 355).

La Reforma Agraria fue uno de los proyectos centrales de los gobiernos posrevolucionarios y debe tenerse en cuenta que si bien su impacto social es de gran envergadura, también lo fue en el plano territorial, pues pretendió generar cambios en las condiciones de acceso a uno de los principales recursos socionaturales: la tierra. En este orden, Craib insiste en que dicho proceso no se despliega desde las altas esferas del Estado y se impone monolíticamente en los distintos ámbitos del espacio rural.

Por el contrario, muestra los conflictos y las negociaciones que se dieron en el ámbito local al momento en que un agrimensor llegaba a un pueblo veracruzano con la pretensión de dirimir un problema de límites para así poder despejar el camino hacia el reparto agrario. Allí, el funcionario estatal se encuentra con un espacio territorializado por distintos grupos sociales, con sus propios conflictos y con sus propias imágenes de lo que es el espacio del pueblo y de la nación. La llegada del moderno Estado nacional al espacio local fue lenta y difícil y debió transitar por los linderos del domino negociado y de la traducción, pues el proceso de deslinde dependía de la información geográfica e histórica que sobre el terreno decidiera aportar la población, poseedora de una suerte de archivo de la memoria territorial. Entonces, 
Craib nos invita a cambiar el lente cartográfico y no solo ver a los científicos que hacen cartografía o los políticos que utilizan los mapas, sino a quienes guían y, en últimas, son los "objetos a cartografiar" (Craib, 2009).

\section{Colombia: el territorio}

\section{nacional, el Atlas geográfico e}

\section{histórico y la disolución de los}

\section{resguardos}

En Colombia, la historia de la geografía y la cartografía del siglo XIX ha tenido a la historiadora Lucía Duque Muñoz como una figura importante. Duque considera que el interés por la historia de la geografía en Colombia se sitúa en el marco del desarrollo de una historia de la ciencia, la cual viene a fortalecerse desde la década de 1980. A su juicio, la historia de la geografía y la cartografía colombianas se ha centrado de manera excesiva en la figura de Agustín Codazzi y la Comisión Corográfica emprendida entre 1851-1859, por lo cual se propone destacar la importancia de otros autores y obras que se dieron antes, durante y después de la citada comisión, además de hacer un inventario de los temas y fuentes que se han tratado o se pueden tratar (Duque, 2006, p. 11).

Para Duque, la emergencia de estos documentos geográficos de mediados del siglo XIX (mapas $\mathrm{y}$ textos) permite evidenciar el desarrollo de una visión estratégica del territorio, que habla de una geografía aplicada y directamente relacionada “con proyectos económicos y políticos" en el ámbito del Estado nación de la época (Duque, 2006, p. 13). Así, en el marco de una suerte de "nacionalis- mo modernizador", la mirada geográfica aparece ligada a la administración del Estado y cumple las funciones de establecimiento de límites internacionales y de levantamiento de la topografía nacional con miras a la implementación de infraestructura y formas productivas acordes a un modelo agroexportador. La obra de Duque permite evidenciar dos temas que aparecen como relevantes: a) la delimitación política de las fronteras internacionales y b) la construcción de una cartografía nacional.

En relación con las fronteras internacionales, Duque considera que si bien el uti possidetis juris de 1810 fue una especie de acuerdo geopolítico para evitar la exacerbación de los conflictos territoriales de las nuevas repúblicas latinoamericanas, para el caso de la Nueva Granada las indefiniciones y desacuerdos fueron comunes. Esto puede ilustrarse en los conflictos por el territorio que tuvo la Nueva Granada tanto con Costa Rica como con Venezuela y con la manera en que desde el Estado se concibieron estos espacios limítrofes.

Respecto a los reclamos territoriales neogranadinos en Centroamérica, Duque muestra cómo los gobiernos de mediados del siglo XIX debieron dar una doble pelea por un territorio marginal y prácticamente desconocido como la Costa de los Mosquitos, actual territorio nicaragüense. Por un lado, estaba el diferendo limítrofe con la República de Costa Rica en torno a la frontera centroamericana de la Nueva Granada, lo cual implicaba, básicamente, establecer los límites territoriales que tuvieron la Audiencia de Guatemala y el Virreinato de la Nueva Granada durante el periodo colonial, una empresa nada fácil de realizar (Duque, 2005).

Por el otro, estaba la intervención británica en la región de la Costa de Mosquitos, que no se limi- 
taba a extraer ilegalmente recursos naturales de la zona, principalmente maderas preciosas, sino que sostenían intercambios comerciales y fomentaban las pretensiones autonomistas en aquella selvática región (Duque, 2005). El conflicto se prolongó y la frontera estuvo indeterminada durante buena parte del siglo XIX, no obstante, la autora destaca cómo, a partir de estos conflictos, se construye una incipiente, aunque previamente inexistente, visión geopolítica neogranadina sobre el Caribe y se desarrollan imaginarios cartográficos y estrategias diplomáticas en torno a la conservación de los intereses nacionales sobre dichas tierras y aguas. Cabe destacar que aquellas indeterminaciones en cuanto al control territorial y a la definición de fronteras en la Nueva Granada centroamericana tienen sus repercusiones en la actualidad con el diferendo limítrofe entre Colombia y Nicaragua en torno al mar territorial y al Archipiélago de San Andrés y Providencia (Duque, 2005).

En relación con la frontera con Venezuela, el uti possidetis juris de 1810 también presentó indeterminaciones y por lo tanto disputas respecto al territorio fronterizo de ambas naciones. Esto debido a que las entidades político-administrativas heredadas de la Colonia, en este caso el extenso Virreinato de la Nueva Granada y la Capitanía General de Venezuela, carecían de una precisa delimitación territorial, lo cual fue problemático al momento de definir las fronteras de los Estados nacionales decimonónicos. Sin embargo, a diferencia de la marginal Costa de Mosquitos, Duque muestra que la situación de la frontera colombo-venezolana atrajo permanentemente la atención de gobernantes y académicos desde los primeros litigios en 1830 hasta 1881, año en que se logra un acuerdo relativamente perdurable. En ello, nos dice la autora, los discursos científicos producidos desde la geografía y la cartografía colombiana fueron fundamentales, pues se apeló a recorridos de campo e investigación en archivos coloniales para sustentar las aspiraciones territoriales del Gobierno colombiano frente a su homólogo del vecino país (Duque, 2009, p. 125).

En relación con la construcción de una cartografía nacional, el Atlas geográfico e histórico de 1889 se constituye en uno de los documentos geográficos más importantes de la Colombia de finales del siglo XIX, por lo cual también ha atraído la atención de investigadores (Díaz, Muñoz \& Nieto, 2010). El Atlas tiene la pretensión de reafirmar el carácter moderno de la nación colombiana, incorporando una serie de rasgos "científicos" como la proyección, el sistema de coordenadas y la escala, características que dan cuenta de un territorio medido y razonado. Según Mauricio Nieto, Santiago Muñoz y Sebastián Díaz, el Atlas tiene la pretensión de constituirse en una biografía espaciotemporal de la Colombia decimonónica, construyendo un relato visual que "entrelaza el espacio y el pasado de la nación" (2010, p. 55) (Figura 3).

Se trata de una narración cartográfica que busca naturalizar y eternizar una entidad política por medio de la representación de unos límites espaciales externos que se "mantienen invariables" desde el siglo XVI. En este sentido, en la lógica del Atlas, el espacio nacional tiene su antecedente en la llegada de los conquistadores, quienes lo recorren, lo dominan y lo civilizan. En esta sucesión de mapas de carácter cronológico y lineal, la Independencia, el otro gran momento fundacional, cobra un sentido similar al de la Conquista, pero ahora son los líderes criollos quienes surcan un espacio cuya complejidad se reduce a ser un teatro de la guerra. Así, 
según Anna Jagdmann (2002), puede decirse que el Atlas refuerza aquella idea presente en la historia tradicional, en donde las élites y a sus próceres se presentan como los artífices de la independencia y los fundadores de la nación (Jagdmann, 2002).

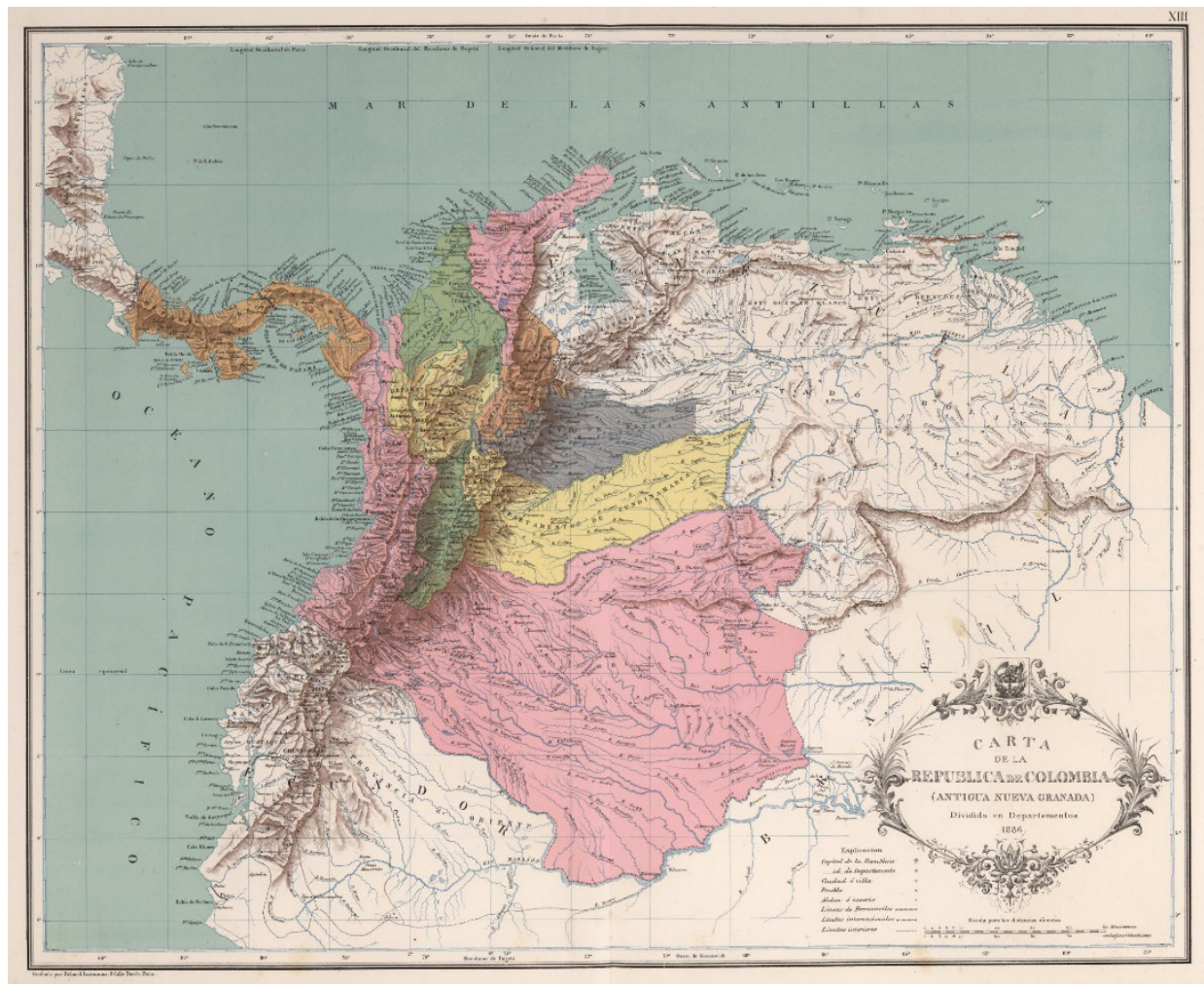

FIGURA 3.

“Carta de la República de Colombia (Antigua Nueva Granada): dividida en departamentos, 1886”: mapa elaborado por Felipe Pérez y Manuel María Paz publicado en 1889.

Fuente: David Rumsey Historical Map Collection.

Finalmente, debe hacerse referencia a trabajos que han tratado de abordar la relación entre cartografía y nación a una escala local en Colombia. En este orden, estudios como el del geógrafo e historiador Juan David Delgado (2020) proponen ver, desde una lente geográfica, procesos tradicionalmente abordados desde la óptica un tanto estructuralista de la historia agraria tradicional. En este sentido, Delgado considera la disolución de los resguardos en la primera mitad del siglo XIX como una de las reformas medulares en la política agraria liberal, en donde se promovía lo que la historiadora Da- niela Marino denomina la "anulación de la propiedad y usufructo colectivo de la tierra y la creación de un mercado libre de tierras, garantizando la propiedad individual, perfecta e irrevocable" (Marino, 2006, p. 33).

Delgado hace énfasis en que la disolución de los resguardos indígenas en la sabana de Bogotá requería, antes que nada, de la conformación de un paisaje racionalizado que permitiese contar con información geográfica consistente, que debía levantarse en terreno mediante técnicas modernas de 
agrimensura que permitiesen la conformación de espacios legibles. El autor entiende por "espacios legibles" aquellos lugares escudriñados y levantados por la lente de la geografía y la cartografía "moderna”, espacios con límites fijos, numerados, avaluados, representados geométricamente. Espacios mensurados y mensurables según las necesidades del Estado nacional. Sin embargo, Delgado menciona que estos espacios legibles eran muy escasos para la época y su conformación demandaba una amplia capacidad logística y presupuestal de parte de los distintos niveles del poder político.

Por el contrario, dice el autor, a lo largo y ancho de las comarcas que componían la república primaba una cierta "opacidad espacial", expresada en formas comunitarias y tradicionales de estructuración del entorno, formas de entender y representar el espacio históricamente constituidas y alejadas de la mirada funcionalista del Estado liberal, espacios construidos por la gente en medio de mil azares. Estos son los paisajes que no habían sido normalizados por la lente de la ciencia y se caracterizan por presentar, citando nuevamente a Raymond Craib, "múltiples jurisdicciones y derechos de uso, fronteras indefinidas y toponimias inconsistentes, así como sistemas de tenencia y propiedad fuertemente contextualizados" (2013, p. 32).

Por tanto, el trabajo de Delgado (2020) presenta un acercamiento a la historia espacial de la privatización de las tierras comunales o resguardos indígenas en la sabana de Bogotá, entendiendo este proceso como una tensión dialéctica entre espacios legibles y paisajes fugitivos (Craib, 2013), tensión que, a su vez, hace parte de un proceso mayor de cambio en el siglo XIX en Latinoamérica: el contrapunteo entre tradición y modernización.

\section{Reflexión final}

Muchos temas, autores y países quedaron fuera del presente análisis. Sin embargo, algunas líneas generales pueden destacarse de lo aquí expuesto. En los tres casos abordados, los distintos autores han hecho énfasis en la forma en el que el desarrollo de las cartografías y las geografías nacionales han acompañado y en buena medida han sido producto del proceso de modernización de los Estados nacionales latinoamericanos en la transición del siglo XIX al XX.

Así, consideramos que los tres casos nos han dejado claro que, en la lógica del Estado, medir es conocer y conocimiento es poder, por lo cual "en tanto no esté medido, el espacio es descomunal, salvaje, indisciplinado, indómito, vacío" y es la encarnación de horror vacui, un espacio sin límites ni fronteras, sin puntos de referencia, el cual se hace imposible de representar y por lo tanto de controlar. Solo al ser medido, el espacio "es doméstico, entrado en razón, razonable, razonado. Sólo territorializado es el espacio dominable y dominado, es espacio de dominio" (Schlögel, 2007, p. 165).

En este contexto, el aporte que debe destacarse en esta reciente historiografía va más allá de la enumeración de los espacios recorridos y cartografiados o del estado de las técnicas y conocimientos geográficos de una época. Ante todo, esta nueva historiografía nos habla de la emergencia de una forma moderna y "racional" para gobernar. Sin embargo, en la mayoría de los textos aquí revisados queda la impresión de que la historia de la cartografía y la geografía en América Latina aún se encuentra aprisionada en el estrecho molde institucional, que en ocasiones no aborda de manera crítica la relación entre la cartografía y el poder. 
Salvo el caso argentino, esta es una historia que continúa haciéndose y viéndose de manera unidimensional "desde arriba", desde los decretos, los institutos geográficos, los intelectuales y sus comisiones exploradoras, desde los mapas hechos o impresos en el extranjero, cuestionándose poco por sus significados culturales, por quienes están "dentro" y quienes están "fuera".

Literalmente, por quienes han sido "borrados del mapa" y, por ende, excluidos del cuerpo geográfico de la nación. Aquí valdría la pena reivindicar la manera en que Jagdman (2002) y Díaz, Muñoz y Nieto (2010) han deconstruido el discurso que se entreteje tras los mapas del Atlas colombiano de 1889 y evidencian la manera en que se naturaliza el espacio nacional, haciendo de la élite criolla los forjadores de la patria.
Finalmente, consideramos que, en la mayoría de los artículos aquí revisados, preguntas o cuestionamientos relativos a los otros, los indios, los negros, los extranjeros, entre otros, han quedado excluidos no solo de los mapas nacionales de fines del XIX, sino también de la historiografía que los ha estudiado. De ahí que sea importante el llamado de Craib a ampliar nuestra noción "mapa" e incorporar otros actores que también participan en el proceso de producción cartográfica: campesinos e indios, baquianos y guías locales, aquellos quienes están en el terreno, lo conocen mejor que nadie y que han permitido que las pomposas comisiones corográficas hayan tenido un relativo éxito. No obstante, el balance general sobre los estudios de historia de la cartografía en América Latina es más que positivo, si se tiene en cuenta lo reciente de este campo y lo mucho que hay por hacer. 


\section{Referencias}

Álvarez, S. (2011). Patrimonio territorial y fronteras: la visión del Estado mexicano en el siglo XIX. En C. Herrejón (coord.), La formación geográfica de México (vol. 1, pp. 70-125). México: Consejo Nacional para la Cultura y las Artes.

Craib, R. (2004). Cartographic Mexico: a history of state fixations and fugitive landscapes. Durham: Duke University Press.

Craib, R. (2009). El archivo en el campo: espacio, conocimiento y deslindes en la reforma agraria mexicana. En H. Mendoza \& C. Lois (coords.), Historias de la cartografía de Iberoamérica: nuevos caminos, viejos problemas. Aguascalientes: UNAM, INEGI.

Craib, R. (2013). México cartográfico: una historia de límites fijos y pasajes fugitivos. México: Instituto de Investigaciones Históricas, UNAM.

Deler, J. (2008). Transformaciones del espacio en América Latina. En Historia general de América Latina: los proyectos nacionales latinoamericanos: sus instrumentos y articulación 1870-1930 (vol. VII). París: Unesco.

Delgado, J. D. (2020). Espacios legibles para la desamortización: La disolución de los resguardos indígenas en los pueblos del cantón de Zipaquirá (Nueva Granada), 18321839. En prensa.

Díaz, S. Muñoz, S. \& Nieto, M. (2010). Ensamblando la nación: cartografía y política en la historia de Colombia. Bogotá: Ediciones Uniandes.

Duque, L. (2005). Límites de la Nueva Granada en Centroamérica: la polémica con Gran Bretaña en torno a la posesión de la Costa de Mosquitos a mediados del siglo XIX. Boletín AFEHC, 10. Recuperado de http://www.afehc-historia-centroamericana.org/ index_action_fi_aff_id_362.html.

Duque, L. (2006). Geografía y cartografía en la Nueva Granada (1840-1865): producción, clasificación temática e intereses. Anuario Colombiano de Historia Social y de la Cultura, 33, 11-30.

Duque, L. (2009). El discurso geográfico y cartográfico colombiano sobre los límites entre Nueva Granada y Venezuela (1830-1883). Anuario Colombiano de Historia Social y de la Cultura, 36(1), 125-152.

García, B. (1975). La Comisión Geográfico-Exploradora. Historia mexicana, 24(4), 485555.

Glumer, Bodo von. (1895-1896). Carta de Comunicaciones de los Estados Unidos Mexicanos. Formada de orden de la Secretaría de Estado y del Despacho de Comunicaciones y Obras Públicas, por el coronel Bodo von Glumer, primera hoja. Grabado e impreso en el Instituto Litográfico de Berlín. Recuperado de David Rumsey Historical Map Collection https://www.davidrumsey.com/luna/servlet/ s/920i7d. 
Gómez, P. (2006). La asimilación de las ideas de Ratzel y la nueva visión del territorio mexicano. Scripta Nova. Revista Electrónica de Geografía y Ciencias Sociales, 10. Recuperado de http://www.ub.es/geocrit/sn/sn-218-25.htm.

Harley, B. (2005). La nueva naturaleza de los mapas: ensayos sobre la historia de la cartografía. México: Fondo de Cultura Económica.

Jagdmann, A. (2002). La biografía visual de Colombia: el Atlas de 1889, leído como símbolo nacional. Revista de estudios sociales, 13, 56-65. https://doi.org/10.7440/ res13.2002.06.

Kuntz, S. \& Speckman, E. (2010). El porfiriato. En Nueva historia general de México (pp. 487-536). México: El Colegio de México.

Lois, C. M. \& Troncoso, C. A. (1998). Integración y desintegración indígena en el Chaco: Ios debates en la Sociedad Geográfica Argentina (1881-1890). Ponencia presentada en el $1^{\circ}$ Congreso Virtual de Antropología y Arqueología NAyA. Recuperado de http://www.naya.org.ar/congreso/relatorias.

Lois, C. M. (1999). La invención del desierto chaqueño. Una aproximación a las formas de apropiación simbólica de los territorios del Chaco en los tiempos de formación y consolidación del Estado nación Argentino. Scripta Nova. Revista Electrónica de Geografía y Ciencias Sociales, 38. Recuperado de http://www.ub.es/geocrit/sn-38. htm.

Lois, C. (2009a). Técnica, política y deseo territorial en la cartografía oficial de la Argentina (1852-1941). En H. Mendoza \& C. Lois (coords.), Historias de la cartografía de Iberoamérica: nuevos caminos, viejos problemas. Aguascalientes: UNAM, INEGI.

Lois, C. (2009b). Imagen cartográfica e imaginarios geográficos. Los lugares y las y las formas de los mapas en nuestra cultura visual. Scripta Nova. Revista Electrónica de Geografía y Ciencias Sociales, 13. Recuperado de http://revistes.ub.edu/index.php/ ScriptaNova/article/view/1604.

Marino, D. (2006). La modernidad a juicio. Los pueblos de Huixquilucan en la transición jurídica (Estado de México, 1856-1911). (Tesis doctoral). El Colegio de México, México.

Meinig, D. W. (2000). The Shaping of America: a Geographical Perspective on 500 Years of History. (Vol. 3: Transcontinental America, 1850-1915). New Haven: Yale University Press.

Mendoza, H. \& Lois, C. (Coords.). (2009) Historias de la cartografía de Iberoamérica: nuevos caminos, viejos problemas. Aguascalientes: UNAM, INEGI.

Mendoza, H. \& Mendoça, S. (2009). El mapa geológico de México y Brasil, 1850-1900. En H. Mendoza \& C. Lois (coords.), Historias de la cartografía de Iberoamérica: nuevos caminos, viejos problemas (pp. 467-494). Aguascalientes: UNAM, INEGI.

Moncada, J. O. (1999). La profesionalización de la Geografía mexicana durante el siglo XIX. Ería, (48), 63-74. 
Moncada, J. \& Gómez, P. (2011) Patrimonio geográfico mexicanos del siglo XX. En C. Herrejón (coord.), La formación geográfica de México (vol. 1, pp. 219-253). México: Conaculta.

Navarro, P. (2006). Paisajes del progreso. La Norpatagonia en el discurso científico y político argentino de fines del siglo XIX y principios del XX. Scripta Nova. Revista Electrónica de Geografía y Ciencias Sociales, 10. Recuperado de http://www.ub.es/ geocrit/sn/sn-218-76.htm.

Otero, H. (2006). Estadística y nación: una historia conceptual del pensamiento censal de la Argentina moderna, 1869-1914. Buenos Aires: Prometeo Libros.

Paz, M. M. \& Pérez, F. (1889). Carta de la Republica de Colombia (Antigua Nueva Granada): dividida en departamentos, 1886. En Atlas geográfico e histórico de la República de Colombia (Antigua Nueva Granada): el cual comprende las repúblicas de Venezuela y Ecuador con arreglo a los trabajos geográficos del general de ingenieros Agustín Codazzi ejecutados en Venezuela y Nueva Granada. Construida la parte cartográfica por Manuel M. Paz, Miembro de la Sociedad de Geografía de París y redactado el texto explicativo por el doctor Felipe Pérez. Todo de orden del Gobierno Nacional de Colombia. París: A. Lahure. Recuperado de David Rumsey Historical Map Collection https://www.davidrumsey.com/luna/servlet/s/0qe4hg.

Radding, C. (2008). Paisajes de poder e identidad: fronteras imperiales en el desierto de Sonora y bosques de la Amazonía. México: CIESAS, El Colegio de Sonora.

Sagredo, R. (2009). Geografía y nación. Claudio Gay y la primera representación cartográfica de Chile. Estudios Geográficos, 70(266), 231-267. doi: http://dx.doi. org/10.3989/estgeogr.0454.

Said, E. (1990). Orientalismo. Madrid: Libertarias.

Sánchez, E. (1998). Gobierno y geografía: Agustín Codazzi y la Comisión Corográfica de la Nueva Granada. Bogotá: Banco de la República, El Áncora Editores.

Schlögel, K. (2007). En el espacio leemos el tiempo: sobre historia de la civilización y geopolítica. Madrid: Siruela.

Smith, A. D. \& Núñez, R. (1998). Conmemorando a los muertos, inspirando a los vivos. Mapas, recuerdos y moralejas en la recreación de las identidades nacionales. Revista Mexicana de Sociología, 60(1), 61-80.

Williams, F. (2009) La exploración de la Patagonia Central y los mapas de Llwyd Ap Iwan. En H. Mendoza \& C. Lois, Historias de la cartografía de Iberoamérica: nuevos caminos, viejos problemas. Aguascalientes: UNAM, INEGI.

Winichakul, T. (1994) Siam mapped: a history of the geo-body of a nation. Honolulu: University of Hawaii Press.

Wysocki, J. (1877). Plano general de la nueva línea de fronteras sobre la Pampa construido por orden del Colonel Dn. Adolfo Alsina [...] Por el Sargento Mayor Dn. Jordan. En Planos de la nueva línea de fronteras sobre la Pampa. Bs. As.: Ministerio de Guerra y Marina, Litogr. de Alb. Larsch, Florida 164. Recuperado de David Rumsey Historical Map Collection https://www.davidrumsey.com/luna/ servlet/s/qicz15. 
Zusman, P. (2006). Paisajes en movimiento. El viaje de Sarmiento a los Estados Unidos (1847). Scripta Nova. Revista Electrónica de Geografía y Ciencias Sociales, 10. Recuperado de http://revistes.ub.edu/index.php/ScriptaNova/article/view/1227. 